\title{
Hawking as a Mirror of Advertisement in African Society: Nigeria as a Case Study
}

\author{
Abodunrin Kemi \\ Department of Mass Communication, Faculty of Arts, University of Nigeria, Nsukka, Nigeria \\ Email address: \\ kemiabod@yahoo.com \\ To cite this article: \\ Abodunrin Kemi. Hawking as a Mirror of Advertisement in African Society: Nigeria as a Case Study. International Journal of Philosophy. \\ Special Issue: Towards the Creation of Technological African: The Imperative of a "New Philosophy". Vol. 8, No. 1, 2020, pp. $15-21$. \\ doi: $10.11648 /$ j.ijp. 20200801.13
}

Received: December 5, 2019; Accepted: January 10, 2020; Published: February 28, 2020

\begin{abstract}
Making goods, services and ideas known to those who need them with the intent of repeat purchase is advertising. However, hawking formed the basis of this art in traditional Africa for which a technology is implied. As a basis to determine hawking's relevance and subscription propensity in the face of mass mediated advertising, responses solicited through interviews from the six geo-political zones in Nigeria and critically discoursed provided quite some premises along Fairclough's thought. The ideals of the study equally tied to the Communication Accommodation Theory by Howard Giles as a social psychology has to do with mindset. Accommodation transverses cultural boundaries and to this study regional dichotomies. The theory emanating from speech accommodation underlies the denominator which is speech in hawking.. With convergence and divergence as key ideas, but accentuating discourse management in relating to topicality preferences between the communicating parties; such that the momentary speaker while haggling underscore divergence. The theory harps on group identity as premised on initial orientation upon which a similarity is established in the Nigerian advertising landscape. Hawking predating towncrying, a development indicator and it was and still is advertisement form were essential findings. Enhancing the craft for national development as well as local government's support of the industry for competiveness was emphasized to accentuate the underpinning frames thereby.
\end{abstract}

Keywords: Advertising, Africa, Development, Hawking, Nigeria

\section{Introduction}

Nigeria as a country continues to evolve like other nations. Evolving means different things to different people. By the reason of the Sustainable Development Goals which is the desired end of nations, development continues to underscore the idea. By the account of Bel-Molokwu, town crying was the formal basis of bringing 'impending development or event' to the knowhow of a people [1]. The Nigerian nation has been primitive and records minimal developmental rate. On development, Wilson retorts "Development is not about physical infrastructures alone but it must be preceded by mind development." [2] It is trite to delineate between development as not tantamount to growth. The former is expansive cum horizontal while the latter is vertical with the arrows upwardly bound. It tends to reason that the former serves as a benchmark for the latter.

Such crude means of informing people like the town crier which is the formal aggregating of ideas already certified by the owner and assented to by the authorities to whom the town crier is answerable comes to the public glare. Therefore, the town crier is likened to the mass medium. While at the hawking stage; the message is still personalised, at most interpersonal. It attains the group stage at referrals. This forms the basis of our reasoning. To Wilson, it is at the interpersonal interface that the mind and psychology are engaged. Our thought echo's the submission of Bel-Molokwu as commerce informing the basis of trade leading to competitiveness and ultimately advertising [1]. Wilson further strengthened the viewpoint of this study's position when he added

I found out that beyond the often misleading concept of the town crier there are diverse dynamic traditional modes and instruments of communication used in the area and in several parts of Africa. These I divided into six classes namely, Instrumental, Demonstrative, Iconographic, Extramundane, 
Visual and Institutional [2].

The author would reason that hawking as argued for comes under the demonstrative (essentially; Music and Signal).

Despite bandying globalization as a fad, Nigeria tends not to be in tandem with current realities by her rating in issues of world reckoning. It is in the same vein that advertising which essentially began by hawking using predominantly word-of-mouth and within the vicinity of prospects for which interested parties call out to see/identify, gives the product/service a trial, repeats the purchase and testifies to others still holds today.

A nexus is seen between the norm and personal selling. Much as formal cum modern advertising occur in Nigeria, the author shows that word-of-mouth, referrals and hawking yet hold the ace in Nigeria. This relates to Idang's reference to arts and crafts coalescing into aesthetics [3]. Nigeria has a teeming population in rural areas $[1,4]$. This equally affirms Ndolo's position of not having a nation develop on the threshold of institutions built by others [4]. This is in tandem with McQuail inter alia foretelling that peripheral nations have no content exports but are quite receptive [5]. A part of being receptive is evidenced in hawking now manifesting as network marketing, testimonial advertising and are a part of personal selling.

While town crying may not be as viable in the face of mass mediated communication, hawking yet holds in its crude state and serves the same purpose(s) it is always known to while the country remains a going concern. Town crying tends to be usurped by the mass media and would now only probably better serve for publicity.

\subsection{The Problem}

Hawking is mostly engaged in the early hours of the day and late in the evenings. It has less cost and a determined radius of coverage due to capacity. Hawking is a mode of employment for which we argue is the base of advertising. Since the products are indigenous and almost have not much international value, the "mass effect" that within the confines of the advertisement corridor is tantamount to the quantity to satisfy that population it garnered. Ndolo has said no nation can grow based on institutions built by another [4]. With a growing population, change in taste and aspiration, competitiveness is the order of the day. In like manner is cross border interaction on the rise. The mass media aids this projection. Cross border interaction comes to play in a state of economic vibrancy, exchange, purchasing power parity and technology savyness. Advertisement then serves a people who are so certified or are demonstrating the attribute to.

Despite being a multi-cultural society, the concept of hawking holds throughout the country and appear not to be subsumed by the advent of technology which is not only in a state of flux but not as available and not exactly accessible. Wilson had expressed his fears that

...traditional communication processes have been ignored for too long. This seeming abandonment of our traditional communication processes and preference for processes that seem to be more efficient but ineffective, faster but limited in effective reach and saturation of the critical population, heterogeneous but alienating, time-saving but expensive modern processes which are after all, culturally threatening to the process of democratization and legitimation, has been a source of concern to committed scholars who have not yet abandoned the obligation to think for themselves [2].

With a thriving advertising platform such as hawking which if not directly subscribed to, people yet do through friends, family and neighbours for wares and services, technological Africanism is observed through this window. While earlier submissions have been in favour of the towncrier as the formal basis of advertising, it is worthy to note that certain activities held before the town-crier's engagement. It is also needful to remind that not all products/services/ideas get to pass through the town-crier.

Therefore, hawking, despite the crux of modernity seem to have a foothold in Nigeria the changing times notwithstanding. This study connects to the three dimensions of the Sustainable Development Goals: the economic, social and environmental with particular emphasis on the 'people' being one of the 5p's (planet, prosperity, peace and partnership being the others) of the agenda (http://www.un.org/en/development/desa/population/migratio n/generalassembly/docs/globalcompact/A_RES_70_1_E.pdf) . It then finds nexus in the submission of Ndolo which opines that: "We have to find cross-fertilize our traditional values and heritages with media technologies developed by us. We have no other country. Let us combine to save her [4]."

\subsection{Study Objectives}

Concerns to this study are to:

1. Determine the extent to which hawking serves in advertising in the face of mass media platforms

2. Ascertain subscription propensity to hawked goods/services in the face of mass mediated advertising.

\subsection{Methodology}

Through interviews based on responses received from randomly selected adults of the six geo-political zones in the country, who should have some level of mastery of their environment as well as information passed to them sourced. Thereafter, meaning was inferred using discourse analysis which Fairclough reported in Ndiribe explain as "all social practices are tied to specific historical contexts and are the means by which existing social relations are reproduced or contested, and different interests are served [14]."

\section{Main Body}

\subsection{Empirical Review}

Bardi's (n.d) account on advertising in Nigeria began with the town criers, hawkers and the act of displays. He recalls formal advertising began with the introduction of the printing press in 1450 but the Iwe Irohin newspapers enabled classified adverts and other types of advert messages. With improved business activities, the Royal Niger Company 
became United Africa Company. The company in a bid to draw attention to its products formed the West African Publicity Ltd (WAP) on August 13, 1928 by the account of Bel-Molokwu cited in Bardi. WAP transmuted to be named Lintas West Africa Ltd in 1965. By continued expansion, Afromedia was established in 1959.

Using the survey research method based on interviews with practitioners and other stakeholders: 6 advertising agencies, APCON (as a regulatory body), OAAN (as a sectorial body), a law maker and 2 other stakeholders of outdoor advertising [7]. This current study expects to evaluate advertising in technological capacity as germane to Africa of which Nigeria is a part; side by side the hawking fad.

With a focus on trends in advertising cultural and creative industries in Nigeria, Olatunji shares the thought on individual creativity with an encompassing scope as constituent. Word-of-mouth, town criers, invention of printing paper by the Chinese and the American space brokers were Olatunji's account of advertising history. In Nigeria, Olatunji recognises: Hawking, word-of-mouth, dance drama and town crier as advert channels. Olatunji reminds the advent of western-type advertising in Nigeria on the threshold of European Corporations - United African Company (UAC). On the language of advertising in Nigeria, Olatunji submit that advertising messages advanced from being of foreign orientation to local flavour with indigenous languages as evidence. Olatunji aside recognizing advertising as informative, educative and entertaining admits it provides 'space for fun and escape'. Space and escape in this sense allows for local content like using celebrities and their ideas for development and greatness [8].

Cage admits that the business undertone of the media. With a focus on newspapers in sub-Saharan Africa alongside records from such countries as Europe and the United States. Cage contends that the report of sub-Saharan African media may not be simplistic with an observed multiplicity of paths to African's media development. Media's dependence on advertising is queried while also questioning the orientation that competitive media is needful.

In clear terms, Cage admits, "there is a dearth of publicly available data on the media sector in sub-Saharan Africa, both for historical and current data." Querying further the age of the press in sub-Saharan Africa, Cage harped on economic and technological development as requirements [9]. The same technology which this study argues is not within the reach of the average Nigerian. For instance, the IweIrohin being the first newspaper in Nigeria emerged in 1859 and it was the brainchild not of Nigerians but a missionary for selfinterest in propagating the gospel cum formal education. Cage's submission of media development in Nigeria skipping the print newspapers phase but beginning at the radio phase is a misnomer [9]. This tends to connect to the argument in McLuhan's Media Ecology Theory.

Media ecology as propounded by Marshall McLuhan and accounted by Griffin, Ledbetter and Sparks draws strength from ecologists who study the environment and people's interaction with it. In the same vein, media ecologists study media environments which result in the change witnessed. $\mathrm{He}$ relates with the media on the principle of symbolic environment - the socially constructed, sensory world of meanings that in turn shapes perceptions, experiences, attitudes and behaviour. To McLuhan, the medium is the message in that the medium adapts and alters the message. McLuhan further attest to the reasoning that because humans are immersed in the environment, differentiating the media and human environment is challenging aware they are human creations and an extension of self. On the complexity of environments, McLuhan again worries over understanding the interface between technologies in major ecological shifts in media over thousands of years. This action forms the basis of McLuhan's argument.

McLuhan captures human history into these periods: Tribal age, literate age, print age, electronic age and finally digital age. To him, the transition is not automatic as there is overlap per phase leading to inventions: between the tribal and literate; invention of phonetic alphabet, between the literate and print; invention of printing press, between print and electronic age; invention of telegraph, between the electronic and digital; there is a stalemate as he insists that electronic media are retribalizing the human race - where everyone is concerned for the other against the literacy age where civilized private detachment prevails unlike the tribal age which is omnidirectional having a primarily communal experience of immediacy and alertness. The earlier stated retribalization of the digital age is premised on the digital age being wholly electronic; altering the electronic though but not producing a distinct (one) electronic tribe of tribal warfare mentality. McLuhan's agitation finds a following in Neil Postman of the New York University's Faustian Bargain arguments - a potential deal with the devil which finds clarification in Postman's expression: technology giveth and technology taketh away i.e. a new technology is never one sided as new technology sometimes creates more than it destroys. Evaluating television, Postman contends society lost more than it gained as public discourse is almost extinct. On the adoption of new technology he suggests an enquiring mind by posing these questions: What is the problem to which this technology is a solution? Whose problem is it, actually? In solving a problem, what other problems will be created? Critics state McLuhan's assertions suggest objectivity without scientific evidence. Proponents desire McLuhan being alive today to reaffirm his stance as he was simply ahead of his time [10].

Looking at the business model of newspapers, in discussing the state of African media currently, Cage affirm that: "In the majority of the sub-Saharan African countries, the advertising market is indeed very tight." The influence is drawn from the undertone of corruption that underlies accessing advertising revenue in a challenged sub-Saharan Africa due to shortfall in resources. In specific terms, advertising as noted by Cage reveal that: "Only in a few countries, the advertising market is growing. This is the case for example in Nigeria." By the reason of Cage's charge 
which follows, this study therefore aspires to respond to the charge of advocating a technologically African concept as is the case for hawking in the Nigeria as a basis for advertisements. The Cage's charge enjoins

African media did not follow the same development pattern as other parts of the world and is not in a satisfactory state - to say the least. At the present time, this is a liability for African democratic and economic development. But this can become an asset if Africa - probably the only continent with sustained population growth in the century under way uses this opportunity to invent a novel model for offering information to new generations of readers, viewers and citizens [9].

Hence this study, that the present author may not be caught in the ring of the charge by Berelson cited in Oso in the $47^{\text {th }}$ inaugural lecture of the Lagos State University, as charged

The innovators have left or are leaving the field, and no ideas of comparable scope and generating power are emerging. The expansion of the field to new centres has certainly slowed down and perhaps even stopped... Some of the newer places are currently repeating what the pioneering places did years ago and are now disappointed with [11]

Ogidi and Utulu recognized traditional media as: television, radio, newspaper and narrowcast media. They further noted the addition of the new media to the foray. They infer the latter's use over the former (termed to be successful) especially among the youths and sought to enquire the possible threats posed by the new media. Ogidi and Utulu however found through interview responses that developing economies like Nigeria have quite a number of illiterate populace thereby making new media less attractive to such group. Also, they find that the new and traditional media are complimentary and the new is therefore not a threat. More so, it was argued that new media has caused a competitive environment as it relates to concerted audience retention in the media. Besides, it was noted that users opinion spread between the two media divide [12]. This study seeks to ascertain the kind of competitiveness that surrounds traditional media in the face of the stiff competition posed as implied by literature.

With a focus on Nigerian culture, Idang observes that as a result of assimilation informed by interface, adjustments are made to cultural dictates. Even a people's technology is inclusive of culture (Idang), Idang further argues that "...we do not have the technological know-how to replace these beliefs that have been abandoned." Howbeit Idang maintained that cultural shift in the mode of advertising tend to be evolving, Idang's assertion of a shift in culture corresponding to a shift in all aspects of culture tend not to be the case as it seem not all aspect of the society shifted towards mass mediated advertising [3]. Wilson's view rather portend

It was clear then that our age of innocence had been passed. Indigenous communication could no longer remain a virgin in the unfolding experience. Even if it had wished to be so, the dynamism of cultural change patterns would not allow it remain untouched and uninfluenced by the ravaging wind of new customs [2].

Has anything then shifted in the advertising scene in Nigeria? And where tends the shift -if any? In his inaugural lecture, Wilson affirms that, "we can understand communication better when we talk about the basics... [2]" With an aim to survey African Media Systems in the Old Calabar Province, an idea he termed 'small media', Wilson referring to a finding of the MacBride Commission insists that, "the world is still speaking with many small voices [2]." Listing small media, it is not impossible that amongst others, it is hawkers they termed 'itinerant loudspeakers.' Wilson's study spanned 1846 to 1986 and in the Old Calabar Province with a technological African perspective demonstrated but this study considers an overview of the Nigerian space.

Looking at how new media impact traditional media of communication in Nigeria, Popoola adducing an explanation through the Uses and Gratification theory observed the relevance of town criers despite mass media channels. Eliciting responses through interviews from first class royal fathers, Popoola reported Oba Fabgamila, who spoke for rural communities as likening the town crier to 'modern radio announcer'. It was maintained that traditional media has a foothold even with the evading presence of new media but the latter is having a full effect in urban communities with possible ripple effect all over overtime [13]. Popoola hinged his study on South-west Nigeria but an attempt to take an overview of the Nigerian terrain with the six geo-political zones as divide is here undertaken.

\subsection{Theoretical Framework}

Communication Accommodation Theory (CAT) by Howard Giles began as a theory rooted in social psychology but gained relevance in communication. Giles idea of communication was that two people emanating from different ethnic groups would normally accommodate each other's approval noted Griffin, Ledbetter and Sparks [hereafter the commentators]. Giles finds that people usually look out for similarity in traits; even of those from different cultures. Giles began developing the theory in 1973 as Speech Accommodation Theory and changed the name in 1987 to CAT focusing more on intercultural communication. The emphasis of Giles in conjunction with his friends had an inter-ethnic communication flavour (as the name implies between the bilingual groups within a country) and in an intergenerational context. In the latter sense, dichotomies are made along age strata of young communicators (teenagers up to adults in their $40 \mathrm{~s}$ to $50 \mathrm{~s}$ ) and senior communicators in the age range group going forward as is applicable in the Nigerian scenario.

The core tenets of the theory according to the commentators termed strategies are: Convergence and divergence. The former bother on adaptation of communication mannerism to enable familiarity; wherein the speaker understands the context of discuss, such as sustaining the nuances when interfacing with an older person. By extension, Giles hints at 'discourse management' which harps on topicality in relation to being deliberate as a means to 
bridge generational gap. Divergence aims to emphasise the differences between speakers by either of the parties. It is about stylistics - language or dialect, accent, speaking rate etc. divergence is intentional; it is about being optimal in communication. Notably, at the point of intergenerational discourse(s), divergence tends to take precedence over convergence. Just as hawking is a tradition passed from the old to the young. Intergenerational encounters gives precedence to age differences, disposition (e.g. being closeminded as it is common with the older generation, short temper and negative generalization). Other variants of divergence are 'maintenance'- communication is sustained without recourse to the other party while over accommodating has a more deplorable effect but is quite excessive in every sense e.g. of vocal clarity, repetition etc.

CAT recognises that we emanate from groups with recourse to them in our communication decisions for social identity. It is this commitment which reinforces divergence not convergence when communicating (between two interactants) due to their salience (allegiance) even when not exactly present. Except people begin to be autonomous individuals, convergence will remain elusive. Divergence or convergence to Giles holds to the extent of an individual's initial orientation; then is implied to mean the predisposition of choice of role play. Initial orientation here is wound around: Collectivist cultural context, distressing history of interaction, stereotypes, norms for treatment of groups and high group-solidarity/high group-dependence for which alignment is subjective and individualistic. Of importance to Giles is not attributing a positive or negative tag to convergence or divergence as was the case prior but to relate with the perception of the other communicator. This finds commonness in stereotypes in relation to image. Giles admits the benefits that accrue from convergent or divergent strategies are relative in terms of who is at advantage per time; this informs Giles submission of either side being an accommodation strategy. Giles cited in Griffin et al explains "CAT can be applied to any intercultural or intergroup situation where the differences between people are apparent and significant." This informs the relationship between the hawker and the buyer/prospects.

\section{Results \& Discussion}

The interviews give more insight into hawking as a concept, activity and as home grown technology which is African and specifically Nigerian. Interviews with six adults from different geo-political zones in Nigeria were respectively tagged:

$\begin{array}{ll}\text { South-east } & \text { A } \\ \text { North-east } & \text { B } \\ \text { North-central } & \text { C } \\ \text { South-south } & \text { D } \\ \text { South-west } & \text { E } \\ \text { North-west } & \text { F }\end{array}$

On a general note, they all agreed that being itinerant informed the status accorded hawking. They also admit all that humans use are hawked in their environments respectively. Hawking has its root in the era of trade by barter specified respondent $\mathrm{C}$ and D. Therefore, Olatunji's submission that advertising messages advanced from being of foreign orientation to local flavour with indigenous languages as evidenced does not hold. Hawking as an indicator of development reveal the country is yet in a transitive state (of development) and most of the citizens depend on it to earn a living. Respondent B differed on the preceding thought by asserting that hawking takes place in advanced economies like the United States.

Responses to items which satisfy study objective one - To determine the extent to which hawking serves in advertising in the face of mass media platforms were varied. The respondents agreed that hawking was and is a form of advertisement while respondent $\mathrm{D}$ out rightly dissented. Meanwhile, respondent $\mathrm{B}$ connects hawking as aiding adverts on television and radio. Services also hawked within these regions are limitless. Howbeit, respondent $\mathrm{D}$ included sex as one of such while respondent $\mathrm{C}$ takes exception by insisting only goods and not services are hawked in the region of the country he hails from. Patronage of hawked goods and services despite advertisements in the mass media is yet rift noted the respondents except respondent $\mathrm{E}$ who implied she does not patronize hawkers. Incidentally, the respondents admit the Nigerian society is ripe for formal mass mediated advertisements save respondent A whose submission negate the view of others premising his argument on aversion towards the media which would then imply minimal or no exposure to advertisements. By serving as a means of employment, hawking serves the nation. Respondent $\mathrm{E}$ mentioned tax payment to the local government as a revenue source to the nation.

To ascertain subscription propensity to hawked goods/services in the face of mass mediated advertising, respondents attribute accessibility to the patronage of hawkers but for respondent $\mathrm{E}$ who did not respond to that question being consistent with her earlier position on patronage of hawked goods/services. Low income earners were noted to patronize hawkers the most while it was suggested that the citizenry were potentials subject to the need at a time (e.g. a traveller). However, respondents B and D intoned everyone irrespective of status buy into hawking. The haves and medical personnel were touted not to patronize hawkers for goods and services; yet, respondent B and $\mathrm{D}$ maintain their earlier position that everyone in Nigeria normally patronise hawkers. When posed if eradicating hawking was an option, respondents took exception to that. Remarkably, respondent A supports its eradication with the hazards of accidents, molestation and rape associated with the practice. On the reverse i.e. retention of hawking being an age long tradition as a pride that should be improved for better delivery, most of the respondents contend for its retention while calling for governments intervention to empower. Respondents $\mathrm{A}$ and $\mathrm{E}$ dissent on the retention of hawking in its current form but request modification through kiosks provision and rebranding. 
Respondents linkage of advertisement to the period of trade by barter suggests Bel-Molokwu's insistence of towncrying as the formal basis of advertising does not hold. Besides, Bel-Molokwu had equally argued for commerce as informing trade leading to competitiveness which results in advertising. For which Wilson described as 'misleading concept' but advancing argument for traditional modes of communication which this study observe hawking most certainly has the demonstrative attribute.

Despite Bardi and Olatunji hinting at hawking, they were not emphatic on the point. Cage and McLuhan had expressed concerns on Africanmedia's development as not being patterned but the former suggest the 'liability' can become 'an asset' when the opportunity to 'invent a novel model for offering information to new generations of readers, viewers and citizens'. This clarion call which resonates in Berelson's charge cited in Oso for 'the innovators' is the pedestal for putting the records right thereby retelling the advertising story in Nigeria through hawking and 'think for ourselves' as Wilson thought through establishing the basics as a premise for a functionality of the small voices that Wilson advance. The submission finds an agreement in Ndolo's charge for cross-fertilization of our traditional values and heritages with media technologies developed by us resulting in the redemptive call. Also, Ndolo's sustained aversion of not premising a nation's development on institutions built by others is valid.

Concerning hawking as a basis for inferring development, whereas Bel-Molokwu in associating town crying as the premise for formality in advertising extend the frontiers of 'impending development or event.' Wilson contest as predating physical infrastructures but mind development. The ability of Nigerians to put their acts together prior to any 'formality' is intoned. Besides, this author argues that not all products/activities/ideas get to pass through the towncrier.

Giles explanation of different ethnic groups (inter-ethnic communication and cultures) yet having similarity in traits finds expression in the nexus of the entire geo-political zones in Nigeria. Convergence is enabled by communication mannerism for familiarity enablement in hawking through discourse management while haggling. Divergence is attained at the point of achieving sales and a need met because that is when being optimal in the interface on respective sides is attained. Again, it is divergence that enables Idang's aesthetics manifest in arts and crafts (in this instance hawking) a technological African ideation. An idea which readily finds appreciable acceptance especially among the teeming population as muted by Ogidi and Utulu, Ndolo, Wilson and Popoola. This author shares this thought and extends the argument further in that the interview outcomes reveal all societal strata patronize hawkers till date.

Acknowledging through convergence, divergence and that 'our innocence had been passed' infer something was and as a result McQuail's foretelling of peripheral nations export quotient as non-existent imply a home grown technology which calls for proper development pattern which cannot remain 'a virgin' in the face of the dynamics of cultural change patterns evidenced in the mass media. We must therefore place premium on the people as hawking is an economy, a social end and environment in the manner of the Sustainable Development Goals.

\section{Conclusion}

Aware hawking served and is still serving in advertising not withstanding mass media platforms, government need seek developmental perspectives to enhance the craft. In like manner, with the admittance of continued subscription to hawked goods/services in the face of mass mediated advertising, local governments need to further the industry as a developmental agenda on the threshold of competitiveness. Technology by this study is getting things done through a process; that we may be seen to be technological Africa. Therefore, advertising in Nigeria as manifest in hawking was and still is in reference to Fairclough's social practices tied to specific historical contexts for existing social relations. This way, certain frames would have attained this study as muted by Abodunrin and Chinweobo-Onuoha that "Framing of a matter reflects the themes ascribed subject matters upon which news content are conceptualised [15]."

\section{References}

[1] Bel-Molokwu, J. A trilogy of advertising: The profession, the practice, the philosophy. Lagos: SefPatri Services Inc., 2017.

[2] Wilson, D. Ethnocommunicology. Trado-Modern Communication and Mediamorphosis in Nigeria: An iconoclast's demystification of some communication traditions, 2015.44 ${ }^{\text {th }}$ Inaugural Lecture, University of Uyo, pp $1-105$.

[3] Idang, G. E. African culture and values, 2015. UNISA Phronimon, 16 (2), pp. 97-111.

[4] Ndolo, I. S. Mass media systems and society. Enugu: RhyceKerex Publishers, 2005.

[5] McQuail, D. Mc Quail's Mass Communication theory (6 $6^{\text {th }}$ ed.). London: Sage Publications Ltd., 2010.

[6] The 2030 Agenda for Sustainable Development A/RES/70/1 (n.d). $\quad$ Accessed $\quad 5^{\text {th }} \quad$ Dec 2018 viahttp://www.un.org/en/development/desa/population/migrati on/generalassembly/docs/globalcompact/A_RES_70_1_E.pdf

[7] Bardi, J. N. Advertising practice in Nigeria: Development, new trends, challenges and prospects, n.d. Accessed $23^{\text {rd }}$ August 2019 pp. 47-54 via https://www.ajol.info > index.php > ejotmas $>$ article $>$ view.

[8] Olatunji, R. W. Trends in advertising and cultures in Nigeria, 2018. Communication Cultures in Africa, 1 (1), pp. 54-76.

[9] Cage, J. The economics of the African Media. Prepared for the Oxford Handbook of Africa and Economics. Department of Economics, Harvard University, LittauerCenter, 02138 Cambridge, 2014. Accessed $3^{\text {rd }}$ July 2018 via https://spire.sciencespo.fr/hdl:/2441/5ut30aqjfo8h69p4jd9j3iu 2em/resources/economics-african-media-cage-2014-1.pdf 
[10] Griffin, E., Ledbetter, A., \& Sparks, G. A first look at communication theory (Ninth ed.). New York: McGraw-Hill Education, 2015.

[11] Oso, L. Press and politics in Nigeria: On whose side? N.d. Accessed $\quad 12^{\text {th }} \quad$ October, 2018 viahttp://lasu.edu.ng/publications/inaugural_lectures/inaugural _47th_lecture_of_professor_\%20lai_osho.pdf pp. 1-76.

[12] Ogidi, O. \& Utulu, A. U. Is the new media superior to the traditional media for advertising, 2016. Asian Journal of Economic Modelling, 4 (1), 57-69.
[13] Popoola, T. New media versus traditional media in Nigeria. n.d. Accessed on $10^{\text {th }}$ June 2018 via http://docplayer.net/39470821-New-media-versus-traditionalmedia-in-nigeria.html

[14] Ndiribe, M. O. Critical discourse analysis. In B. M. Mbah (Ed.) Theories of contextual linguistics. (pp. 137-148). Anambra: Amaka Dreams Ltd. 2017.

[15] Abodunrin, K. \& Chinweobo-Onuoha, B. N. Framing of the Nigerian 2015 general elections postponement by selected national newspapers. (Paper presented at the $17^{\text {th }}$ Annual ACCE Conference Unical, 20-23 October 2015). 